\title{
Path of the Information Asymmetry of Asset Backed Securitization-Information Game Analysis of Embedded Block Chain Technology
}

\author{
Xiaoxiao Zhang',2, Wen Shi ${ }^{3}$ \\ ${ }^{1}$ PBC School of Finance, Tsinghua University, Beijing, China \\ ${ }^{2}$ China Development Bank, Beijing, China \\ ${ }^{3}$ Xiaomi Communication Ltd., Beijing, China \\ Email: zhang_xiaoxiao@cdb.cn, shiwen@xiaomi.com
}

How to cite this paper: Zhang, X.X. and Shi, W. (2018) Path of the Information Asymmetry of Asset Backed Securitization-Information Game Analysis of Embedded Block Chain Technology. Int. J. Communications, Network and System Sciences, 11, 133-146.

https://doi.org/10.4236/ijcns.2018.116008

Received: May 29, 2018

Accepted: June 25, 2018

Published: June 28, 2018

Copyright $(9) 2018$ by authors and Scientific Research Publishing Inc. This work is licensed under the Creative Commons Attribution International License (CC BY 4.0).

http://creativecommons.org/licenses/by/4.0/

\begin{abstract}
In recent years, the rapid innovation and development of financial industry has made financial enterprises have a lot of information. However, the large amount of information is tampered with and fragmented, which cannot be shared. With the constant innovation of science and technology, it is the most effective way to solve the information lag and asymmetry of financial products. This article aims to start from the problem of asymmetric information of financial products, the analysis of the emerging block chain technology applied in the financial sector, and with the development of asset securitization information known as the typical scenario for the first time, a concrete analysis information game process, and discuss about the application of chain blocks in securitization feasibility.
\end{abstract}

\section{Keywords}

Block Chain, Information Asymmetry, Information Game, Asset Backed Securitization

\section{Introduction}

Finance is often seen as a financing channel which can help the entity industry. It is an intermediary organization which can avoid incomplete and asymmetric information. A healthy and stable financial environment could be conducive to the rational allocation of social resources, and the development of the entire economic environment. However, in the real world, financial fraud and moral hazard have occurred frequently, and information asymmetry has become the root reason of various problems in financial field. 
After the US subprime crisis, the culprit was the issuance and trading of securitization. International study of asset backed securitization is becoming deeper. A lot of research and analysis showed that the cause of the crisis is not the asset securitization product itself, but the information asymmetry in each process of asset backed securitization among participants which make the different expectations, eventually led to the crisis.

The most effective solution to the problem of information asymmetry is the high frequency disclosure of information. At this time, the rapid development of information technology makes the high frequency information disclosure possible.

Blockchain is a science and technology innovation emerging recent years. The practical application in finance of blockchain has been begun to explore. It has become a hot spot of the United Nations, the international monetary fund and research institutes. Many information science and technology industry have also stepped up efforts to blockchain research and practice. The construction of blockchain network can solve the problems of information asymmetry and loss of trust in finance.

This article aims to, starting from the problem of asymmetric information of financial products, analyze blockchain technology applied in the financial sector, and analyze the information game with the development of asset backed securitization information as the typical scenario, and try to talk about the feasibility of the application blockchain.

\section{Literature Review}

\subsection{Information Game under Asymmetric Information of Financial Products}

Zhang Yan (2005) [1] believed that efficiency and fairness of the securities market are in close relationship with the publicity of information disclosure of listed companies. The collusion behavior of Information transfer agents and information providers will cause great damage to the financial market fair. In the view of Tian Feng [2], the adverse selection and moral hazard of asymmetric information exist widely in commercial bank credit market. The profit model of commercial Banks makes it inevitable that it will encounter these risks in operation. Moreover, it is proved that symmetric information contract is not optimal under asymmetric information. Yang Jun's (2004) [3] research shows that because of information asymmetry, the cost of domestic companies to distort financial statements is low, it is no separating equilibrium and confusion equilibrium, financial leverage risk identification effect has reduced. Padilla and Pagano (2000) [4] observed that the information sharing among investors will encourage the borrower to try harder. Qian Zhitong and Kong Liuliu (2015) [5] considering the current situation of information asymmetry in the P2P market, constructed the game model with incomplete information with the P2P network platform and loan borrowers as participants, In order to realize the Pareto optimality of P2P market as the research objective, they discussed two different cases, the 
mixed equilibrium and separating equilibrium, and find market conditions of the Pareto optimality.

\subsection{Blockchain: The Best Tool to Solve the Problem of Information Asymmetry in the New Round of Financial and Technological Revolution}

Elvira Nabiullina (2016) [6] said that many central Banks around the world are paying close attention to and the development of blockchain and paying attention to the feasibility of blockchain in innovative finance.

Blockchain technology is to deal with asymmetric encryption technology using digital signatures. It is a distributed books system built by a multi-node agreement using consensus mechanism, and its data is stored in the form of chain block organization. China blockchain technology and Industry Development Forum (2016) [7] thinks that blockchain is a totally new kind of distributed infrastructure and computing paradigm. It verifies the data transmission and data storage using block chain data structure. It generates and updates the data using distributed node consensus algorithm. It ensures the security of data transmission and access using cryptography. It programs and operates data using the flexible script code and intelligent contracts.

The British government's chief scientific adviser Mark Walport (2016) [6] thinks that distributed books technology has the ability to against attacks with its technical characteristics. In this network, there are multiple sharing a copy of the database. The network consensus also can prevent unauthorized malicious tampering behavior, and effectively control the risk of a single point of failure. Jack Markell (2016) [6] believes that the blockchain technology needs to combine with the legal system.

The European securities and markets authority ESMA (2016) [6] thinks that the application of the blockchain distributed books technology can solve the trading volume, extensible, privacy and other issues, as well as reduce the cost, improve the benefits of market efficiency, and can lower the occurrence probability of centralized system network crime.

\section{Information Game in the Asset Backed Securitization}

Based on the relatively rapid development in China in recent years and under the circumstances of the economic downturn, the asset backed securitization is a typical application scenario analysis. Its participating institutions are very abundant, covering from the front end borrowers to the after end investors. In the asset backed securitization products, relevant information including the business of the original borrowers, rating of asset backed securitization, credit and other relevant information, the scope of its information content is very rich.

The following will analyze the information asymmetry of the asset backed securitization and the game process of the related principal organs. 


\subsection{Problem of Asset Backed Securitization: The US Subprime Crisis in 2008}

Yang dong (2012) [8], believed that the excessive securitization is one of the important factors that cause the US subprime mortgage crisis. In the peak, the US financial market had trillions of dollars in securitized assets scale and the fundamental asset backed securitization is derived arbitrary, the underlying assets serious distortion, and the market no longer had the foundation of stable cash flows. Under the high pressure of the rising interest rates and falling house prices, the financial crisis broke out. Hanson and Sunderam (2013) [9] thought that as the subprime crisis happened, the sensitive information hidden behind the securitized products exposed, unwitting investors were reluctant to continue to invest into the securitization market, and eventually triggered the collapse of the entire financial market. Based on the subprime mortgage securitization market analysis in the subprime crisis, Ashcraft and Schuermann (2008) [10] found the adverse selection and moral hazard become core friction in the process of asset backed securitization, and eventually led to the collapse of the securitization market.

\subsection{The Ex-Post Information Asymmetry Problem in Asset Backed Securitization}

Keiichi Kawai (2015) [11] believes that the static adverse selection model in the asset backed securitization shows that the information disclosure of the issuer cannot perfectly disclose the asset information packaged in the asset backed securitization products. Peng Siyuan, Yang Mei (2016) [12] believed that the legal essence of the asset backed securitization is to design a dynamic structural, and give the underlying assets an independent credit qualification, issue the asset backed securities, and then trade in market.

From the perspective of information game, information asymmetry runs through the whole operation process of asset backed securitization. About the theory of financial intermediary theory, Leland and Pyle (1977) [13], thought that in the early asset backed securitization research, the bank's retained part of loan in the process of loan securitization (for sale), could bring positive signals to investors, and deal with the "lemon problems" lead by asymmetric information.

In general, asset backed securitization product design processes including set a securitization assets pool, set up a special purpose vehicle, filtrate the underlying securitization assets in the pool, isolation the assets, credit rating, issue the securities and trade in the secondary market finally. In the whole process, there are many key links need the information of securitization, such as the quality of underlying assets, the delivery of securitized asset pools, credit enhancement, and credit rating.

China had already made a guidance for the securitization asset information disclosure, and also has issued the "personal auto loan asset backed securities information disclosure guidelines 'and' personal housing mortgage loan asset 
backed securities information disclosure guidelines", but there's no specific law regulations. The information of the underlying asset is not disclosed fully and timely, and investors cannot grasp the risk of asset backed securitization products accurately. So the asset backed securitization market information asymmetry phenomenon is serious.

\subsubsection{Information Asymmetry of Underlying Assets}

Quality of underlying asset is the most important information throughout the entire asset backed securitization product, in the whole process of the asset backed securitization, the information of the underlying assets exist obvious asymmetry. The issuing bank was most familiar to situation of the underlying asset. It can get enterprise's financial data immediately, and understand the business situation of the enterprises, then establishment the statistical description information of the asset.

SPV, as the purchasers of underlying assets, usually is a Shell institutions, it does not actually participate in the operation of the securitization, and it also does not pay attention to quality of assets in the asset pool. The major concern of SPV is the relationship between the assets quality and the price of the underlying assets, if there exist the asymmetry of information, the price of the underlying asset may be inflated. Due to the asset sellers are in the advantage of the underlying asset quality information, so the price may not be lower than the actual value of the asset.

Investors' acknowledge of the underlying asset is limited to the information of the underlying asset packaged and calculated by the issuing bank. And obviously in the investment and subsequent holding period the investors are always in the disadvantage situation of the asset information.

\subsubsection{Asymmetry of the Rating Information}

SPV need to pack the underlying asset in the pool and also need to rate and enhance the rate of the underlying asset. But in the trading relationships, credit rating agencies are third party inspection institutes that commissioned by the issuer of the asset backed securitization products, and the rating fees are paid by the issuer. Obviously, this benefit relationship between the issuers and the third party inspection institutes will have guide effect to the result of rating. In the following period after issuing the rating agencies of securitized products have not any fault responsibility.

But at the same time, in the long time the third party inspection institutes may also concern that if the assets in the product decrease after issuing, investors will no longer trust the rating agencies any more, and the authority of the third party inspection institutes is reduced, and affect the reputation of the third party inspection institutes.

\subsubsection{Asymmetric of Securitization Structure Information}

Asset backed securitization is a complex structured derivative. Their internal assets structure is also complex. It has many levels of debt relationship. The origi- 
nal underlying assets were sale by layers after the assets are pooled. Compared with the original underlying asset, the securitization products have had great changes. The issuer and the SPV have many spaces to operate in the process, so the terms of the securitization product may be benefit to the issuers and SPVs.

Investors cannot understand the underlying asset quality in the securitization asset pool through the layers of product structure. So it is hard to the investors to judge their own purchase behavior.

\subsubsection{Asymmetry of Information in the Process of Securitization}

In process of securitization issuing and purchasing, the broker as the underwriters of asset backed securitization products want to sale the products as much as possible. So the brokers have the motivation to make introduction of the product more attractive. To pursuit of sales profit, the brokers maybe possible to conceal risks of the securitization, and this action can lead to the risk of moral hazard.

\subsubsection{Construction of Game Model}

The relevant parties in the above process are divided into four categories. The first type institution is the original debtor. The second type institution is the original creditor and the special purpose vehicle. They are both the main initiators of the asset backed securitization products. The third type institution is related third party organizations, including accounting company, law firms and rating agencies, which are responsible for endorsing and opinions on the structure of the asset backed securitization products. The fourth type institution is the investors, the final product buyer and the risk taker.

Here we mainly discuss that asymmetry problem of asset backed securitization product, do not include front end of the securitization product. After the securitization product issuing, the relationship of bank and original obligors had been established. The loans had been released, the debtor-creditor relationship had formed, the loans had entered into the post-loan stage, and the underlying assets had been brought into the asset backed securitization asset pool. Therefore, this article does not consider asymmetry of ex-ante information of the securitization.

This paper mainly discusses the game model, and separates the analysis into two stages. The first stage is the game between the second type institution and the third type institution, the second stage is the game between the third type institution and the fourth type institution. And we assumed that all the players are rational in the game model, at the same time, the participants are all risk neutral.

Stage 1: The information game between the originator and the third parties

Special purpose vehicle issued an asset backed securitization product which has a total amount of $X$. This asset pool had two kind of loan. One is high quality loan A, whose average yield is $r_{a}$. The other is a bad quality loan B, whose average yield is $r_{b}$. The probability of the high quality loan $\mathrm{A}$ is $q$, and the probability of the bad quality loan B is $1-q$, while $q \in[0,1]$.

The overall loan yield of the asset pool is $r$. 


$$
r=q r_{a}+(1-q) r_{b}
$$

Special purpose vehicle need to hire a third party for the evaluation of securitization, and take the endorsement and the opinion on finance, credit and the legal. Assume the fee is c and the evaluation of third party appraisal cost is $E$.

At this time, in the existing product development mode, special purpose vehicle in the advantage of the information. And this may lead the asymmetry of information between the third party institutions and the original creditor. So there is the possibility of moral hazard. Third parties' responsibility is to review and evaluation the finance situation, risk, credit and legal problems of the asset in the pool objectively and fairly. And the third parties should descript the asset pool and endorsement of the asset pool and higher the credit score. However, the third parties' evaluation cost is paid by the special purpose vehicles, and the cost of the fee is $c$, and here is the problem of agency relationship that is often discussed in game theory.

In order to improve the yield of asset backed securitization $r_{s h}$, special purpose vehicle may pay more valuation fee which is $c_{h}$. The SPV may ask the third parties to evaluate a higher score of the asset pool, and conspire with the third parties through the relationship between the agent and the mandatory. This behavior will increase the income of SPV and the third parties. But damage the interests of investors in the backend.

In this case, if in the subsequent the original debtor defaults, we suppose the default probability is $\mathrm{p}$, the credibility of the rating agencies will lost $L_{g}$. If the original debtor doesn't defaults, subsequent probability is $(1-p)$, both sides will get excess profits. If the special purpose vehicle and evaluation mechanism are not conspiring, the special purpose vehicle will pay a lower fee rate $c_{b}$ which may lower the yield of securitized products to $r_{s l}$. After the issuance of the asset backed securitization products, the bank can continue to invest and the expected yield is $r^{2}$.

In the situation of conspirator, if the bank decides to securitize the asset, the yield will be $r-c h-r s h+r^{2}$. Under the probability of default $\mathrm{p}$, the third parties will have a Lg lost in the goodwill, and the yield will be $X c h-E-p L g$. If the bank decides not to securitize after the evaluation, the yield of the bank is $r-c_{h}$, the third parties' yield will be $X c_{h}-E$. In the situation of no conspirator, if the bank decides to securitize the asset, the yield will be $r-c_{l}-r_{s l}+r^{2}$, the third parties' yield will be $X c_{l}-E$. If the bank decides not to securitize after the evaluation, the yield of the bank is $\mathrm{r}-\mathrm{cl}$, the third parties' yield will be $X c_{l}-E$.

Game model established as Table 1.

Table 1. First stage game model.

\begin{tabular}{ccc}
\hline & Conspirator & No conspirator \\
\hline Securitization & $\left(r-c_{h}-r_{s h}+r^{2}, X_{c h}-E-p L_{g}\right)$ & $\left(r-c_{l}-r_{s l}+r^{2}, X_{c l}-E\right)$ \\
No securitization & $\left(r-c_{h}, X c_{h}-E\right)$ & $\left(r-c_{b}, X c_{l}-E\right)$ \\
\hline
\end{tabular}


Here we could see, in this game model, we cannot find a perfect Bayesian equilibrium of incomplete information dynamic game.

If we bring the blockchain technology into the securitization market, the information of the underlying asset could be shared as much as possible, and receive the target of information symmetry. Under this assumption, the bank does not need to conspire with the third parties. If the bank decides to securitize the asset, the yield of bank is $r-c_{l}-r_{s}+r^{2}$, the yield of the third parties is $X_{c}-E$. If the bank decides not to securitize the asset, the yield of bank is $r-c$, the yield of the third parties is $X_{c}-E$.

In this model, when $r^{2}>r_{s}$, the bank can choose to securitize the asset, otherwise, not to securitize the asset.

Stage 2: The information game between the issuers and the investors

In order to simple the model, this paper does not consider the self-maintaining of the subordinated tranche of the securitization and the layered rating of the underlying asset.

With the existing product development mode, in the process of asset backed securitization products, the issuer has the responsible for the disclosure of underlying asset of the securitization products. But as the underwriting institution charge the fee which is written as rate e in the process of issuing, the underwriter is not neutral. So the underwriting institution may choose to hide the negative information of underlying asset, due to the profit-push.

Here we assume the issuers can get a rate of return $\mathrm{R}$ when the issuer hides the information of underlying asset. The investors will overestimate the quality of the underlying asset, and underestimate the risk of default, so investors will accept lower yields of the securitization product as $r_{s}$. But in the subsequent management of securitization products, the underlying assets have the probability for the default behavior as $p_{s}$. When the investors found the underwriters' deliberate hidden information behavior, the underwriters will have the reputational damage as $L_{m g}$. On the other hand, if the underwriter considered the moral problem, and did not hide the important information of the underlying assets, the yield of the investors can come back to the normal rate as $r_{s}$.

Assume that the market no risk-return rate is $r_{0}$, the game model is as following Table 2.

So when $R-p_{s} L_{m g}>0$, which means the yield after the hidden of the asset information, is higher than the reputational risk losses, the underwriters will help issuers to hide the information of underlying asset. In this case, $p_{s} r_{s l}-e>r_{0}$, which means the expected yield of asset backed securitization is greater than the

Table 2. Second stage game model.

\begin{tabular}{ccc}
\hline $\begin{array}{c}\text { Whether the investors purchase } \\
\text { the securitization product }\end{array}$ & $\begin{array}{c}\text { Underwriters hide } \\
\text { information }\end{array}$ & $\begin{array}{c}\text { Underwriters do not hide } \\
\text { information }\end{array}$ \\
\hline Purchase & $\left(p_{s} r_{s l}-e, e+R-p_{s} L_{m g}\right)$ & $\left(p_{s} r_{s}-e, e\right)$ \\
Do not purchase & $\left(r_{0}, R\right)$ & $\left(r_{0}, 0\right)$ \\
\hline
\end{tabular}


risk-free rate plus a commission fee, the investors will choose to buy the assets backed securitization product.

If we apply the new technology blockchain in the asset backed securitization market, the information can share furthest, and reach the situation of the information symmetry, and the underwriters will no longer have the possibility of hidden information. If the investors buy the asset backed securitization products, they will have the yield of $p_{s} r_{s}-e$, the underwriters will get the commission rate of $e$, if they do not buy the product, the investors can only get the risk-free rate $r_{0}$, and underwriters can't get a commission fee. So when the expected yield of the asset backed securitization is higher than the risk-free rate plus commission rate, the investors choose to buy the securitization products.

Though the game process, we could see the information game process is emphasizing the information synchronization timeliness and accuracy, they are the main factors affecting the results in the game. So to solve the information asymmetry problem of asset backed securitization product, the product information could be more transparent, the purchasing willing of investors will be much higher. This will promote the securitization market prosperity and development.

Therefore, a new technology is needed to help the participate parties in the whole securitization processes to share information better and solve the problem of information asymmetry.

\section{Blockchain Technology Applied in the Asset Backed Securitization Market}

Starting from 2012, as the explosive development of the Internet financial, many kinds of financial platform, internet financial platforms and Internet + mode emerge constantly, especially the P2P platform. In a certain extent, this mode leads the effect of the financial disintermediation. But these years there are a few Internet financial P2P platforms had collapsed or run, the credibility and authority of the Internet financial had been suspected by the financial industry and public.

\section{Blockchain: a trusted technology platform}

The emergence and development of blockchain technology provides a more credible technological path for financial intermediaries. The blockchain can be divided into public chain, private chain, and union chains according to its application scope. The public chain is mainly used for digital currency and provides transaction verification mechanism. The private chain is a trading verification system used by limited membership scope, but does not need to provide virtual digital currency as a reward to verify and incentive the transaction. The alliance chain sets each node on the chain, and confirms the identities through the consensus mechanism. The alliance chain does not need to provide virtual digital currency as a reward to verify and incentive the transaction.

Blockchain as a technical information intermediary, it constructs an efficient and reliable information transmission network, and realize the transformation 
among the multi-center though the digital resources structured by distributed books. And the blockchain could realize the business logic of the multicenter collaborations though the intelligent contract. The practice of blockchain can change the traditional pattern of business collaboration, from inefficient coordination based on participating business process, upgraded to the high efficiency, high credible and low cost cooperative network rely on nothing mediation.

Figure 1 shows the information transfer mode and the system deployment mode and information structure changed by blockchain technology.

Decentralize. Different from the centralized network mode, the status of each node in the blockchain is equal, and each node in the blockchain network has the same rights and does not exist on a centralized server.

Automation. Based on the automated economic activities and contracts of the smart contracts, the blockchain can record the information and the process status, and the data cannot be tampered, and the whole process information monitoring can be realized.

Be trusted. Records cannot be tampered with, do not need third trusted intermediaries.

In the blockchain network, each node could storage the complete and consistent history information through the asymmetric encryption algorithm. If the individual node of book tampers or attacks the data, this behavior will not affect other nodes and will not affect the safety of the general ledger. Because there is no uniform centralized server, there will be no possible of single portal attacks.

Application feasibility verification of asset backed securitization products

The trading behavior of asset backed securitization is an investors trade process participated by many relevant participants. There are certain limits to the participants. At the same time in order to avoid the review resistance problem of the public chain, here the asset backed securitization product applied to the sub classification block chain-alliance chain to use the advantage of chain block, as far as possible to solve the trading information asymmetry problem in the whole process of product.

First, all participants of the asset backed securitization products need to join the alliance chain as the members of the alliance. Members can be divided into two kinds, one kind is the order nodes, they are the common nodes on the chain of the alliance. They build the main body behavior as the alliance chain management nodes, and build the regime of the chain. But there is a limit in the number of the order nodes under the existing technical framework. The other type is Peer node, which can have an infinite number of participating nodes and only record the information of asset backed securitization transaction and accounting information.

Second, in the issuing process of asset backed securitization products, the parties have to provide the relevant information in block chain, to help the investors do the decisions for the sponsors, underwriters and investors. Third party agencies also need the underlying asset information to explain the additional instruction. 


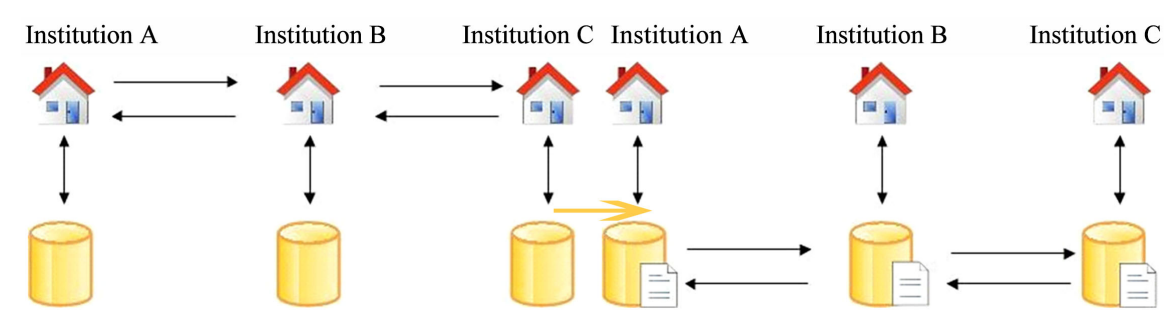

Figure 1. Changes of information structure before and after the blockchain appears.

Again, in the whole life cycle of asset backed securitization, the responsible party of the underlying assets needs to supervise the quality information of the underlying assets in time and keep the information in the blockchain updated.

Finally, the investor will price, quote and follow up the secondary market trading according to the underlying assets information in the block chain.

The access of the block chain books information is limited to the production of the relevant asset pool of borrowers, the basis of the issuing bank, special purpose vehicle of the asset backed securitization, accounting firms, law firms, the rating agencies, securities companies, the underwriters and investors who join the alliance chain as the important part of asset backed securitization. The block chain is using the multilevel encryption mechanism based on cryptography, to ensure the safety of information dissemination under the privacy control.

At the same time, the permissions of each kind of entities or nodes should be set up separately to ensure the data isolation and reliability of information.

Figure 2 is the ledger structure designed in this paper.

The issue of an asset backed securitization products means that adding one block information in the books of block chain structure, including the multiple underlying asset information of the asset backed securitization products, the third party credit rating information, the structure of the asset backed securitization, sale information and investors trading information, etc. Nodes on the chain block can be confirmed by consensus mechanism, according to its own setting of the node permissions in asset backed securitization product chain. The nodes update the asset backed securitization block books information to supervise the behavior of the participants and to do the real-time accounting checking, and to finish the trading based on intelligent automated contract. This could ensure that the records do not to tamper with, without a credible third party as an intermediary intervention.

Such alliance chain structure, can greatly reduce the allopatric transaction cost and time, and could make the parties have relatively complete information faster, and simpler and more efficient than the existing fragmented information system.

Based on the above design of the technology in block chain of the credit asset securitization product, this paper discussed how to improve the asymmetric information situation in the traditional model. 


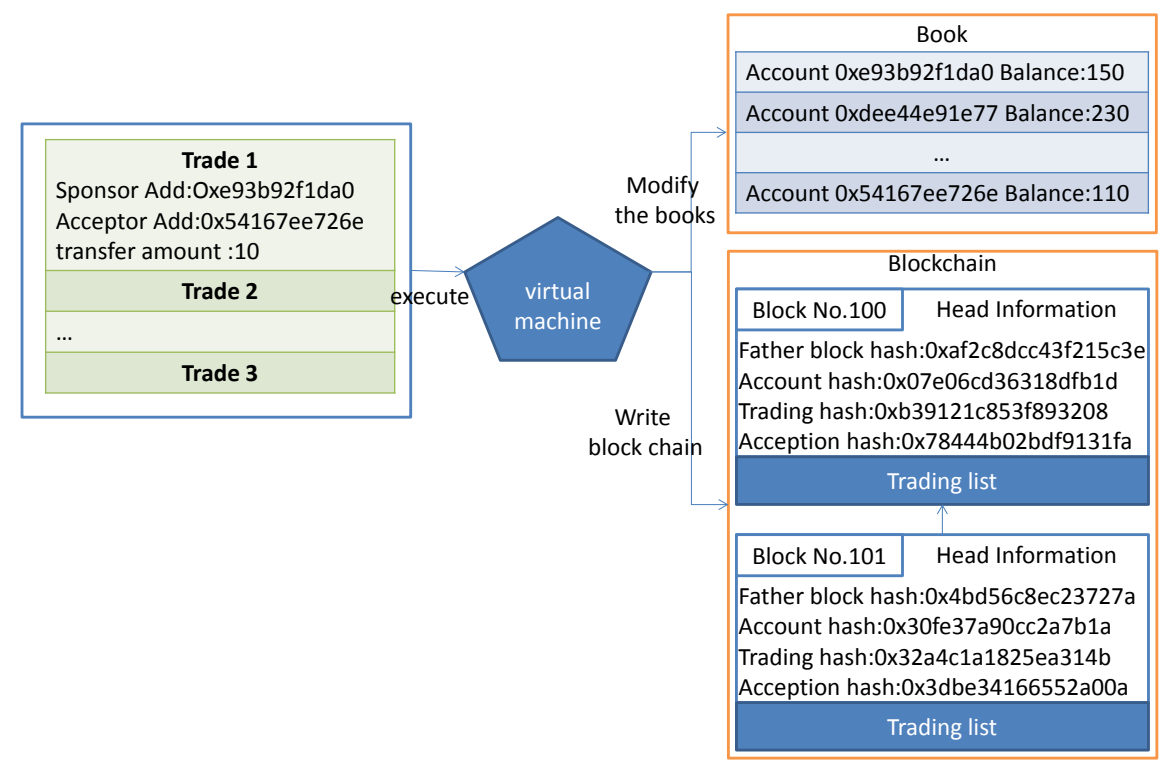

Figure 2. Smart contract and account structure of the block chain in asset backed securitization.

The possibility of asymmetry exists in underlying asset information. The information of the underlying asset comes from the original debtor. It is the most important information in the block chain in the whole life cycle of the asset securitization product. Once the underlying assets changes, the original debtor has the obligation to update the asset quality in the block chain information module, and make sure all related parties in chain could receive their financial data in time, understand the business conditions without any statistic, thus to improving the information quality under the traditional mode of packaging evaluation process, to provide the original basic information for investors, finally to achieve the goal of information symmetry.

The probability of information asymmetry exists in the rating process. Because of block chain technology, all participants can have no time lag to share the quality of the underlying asset data and information. So the asset credit rating information for each participant is relatively transparent. Even if the rating agencies and the issuing bank of asset backed securitization product has economic interest relations, under the transparent information sharing mechanism, investors will also be very sensitive to the rating result. And the cost of wrong evaluation will be greatly increased. In this case, there will be no information asymmetry in the rating process.

The possibility of asymmetry exists in product structure information. Under the block chain technology, the derivatives of the securitization of credit assets structure is no longer be concealed by the multiple layers of the structure. Even after the assets were pooled, investors can also screen the layered underlying from the large amount of asset information, and supervise the changes of the underlying assets. But the complexity of the derivatives structure is not changed because of block chain technology, therefore, even if the situation of the infor- 
mation symmetry is improved, the understanding of investors in the securitization products information also did not have obvious improvement.

The possibility of information asymmetry exists in the trading process of securitization. Due to the use of chain blocks, there no longer exist information asymmetry and the situation of the information lag between the investors and the sellers. So there is no potential possibility to hide the information, and the risk of moral hazard can be effectively controlled.

\section{Summary and Break Path Recommendations}

In recent years, with the rapid innovation and development of the financial industry, the different sectors of different industries had owned a great deal of information. However, the large amount of information capacity is divided by different institutions. The enterprises and industries did not share the information for their own interests. So there exist many information isolated islands.

At present, asset backed securitization's product distribution announcements, information disclosure and trading are mainly in the OTC market. And the trading must follow the restriction of market participants and trading rules in the OTC market. But the OTC market was not designed to serve the whole process of the forming of the asset pool, the product distribution, subscription, holding and deals expire of the asset backed securitization product particularly, so there exists the information asymmetry situation in every link of the product.

With the continuous innovation of science and technology, the new technology is the most effective way to solve the problem of information lag and asymmetry of financial products. In order to prevent the information asymmetry to the asset backed securitization product and the potential danger in the market development, this paper analyzed the information symmetry based on the process of construction and trading of the typical financial products, assets backed securitization, to avoid possible problem under the traditional trading mode, and established asset backed securitization alliance chain using the block chain characteristics and advantages. We should form a single asset backed securitization alliance blockchain. In this chain, the sponsor banks and supervisors are the important node, and other institutions are the participant nodes, they all get the consensus agreement on the business rules of the industry.

So, it is important to create an alliance chain structure based on the issuing and trading of the asset backed securitization product, to solve the problem of the information asymmetry, to avoid the moral risk of participants in the greatest degree, and to build a fair and healthy investment environment for the investors.

\section{References}

[1] Zhang, Y. (2005) Information Game between Agents and Information Providers in China's Securities Market Information Transmission. Journal of Sichuan University, No. 2, 13-21.

[2] Tian, F. (2008) Asymmetric Information Game of Commercial Bank Credit Market 
and Agent-Based SWARM Simulation. Doctoral Thesis, Guiyang, Guizhou University.

[3] Yang, J. (2004) Financial Leverage-Signal Game and Credit Risk Identification. Financial Research, No. 2, 71-78.

[4] Padilla, A.J. and Pagano, M. (2000) Sharing Default Information as a Borrower Discipline Device. European Economic Review, 44, 1951-1980. https://doi.org/10.1016/S0014-2921(00)00055-6

[5] Qian, Z.T. (2016) Research on Internet Lending Behavior under the Perspective of Incomplete Information Game, Taking P2P Network Loan as an Example. Mathematical Theory and Application, No. 6, 110-117.

[6] The UK Government Chief Scientific Adviser (2015) Distributed Ledger Technology: Beyond Block Chain. A Report by the UK Government Chief Scientific Adviser.

[7] Ministry of Industry and Information Technology (2016) China Block Chain Technology and Application Development White Paper. China Block Chain Technology and Industry Development BBS.

[8] Yang, D. (2012) The Experience of Financial and Legal Innovation in Japan and Korea-From Securities Law to Financial Services Law. Contemporary Financier, No. 9, 54-55.

[9] Hanson, S.G. (2013) Are There Too Many Safe Securities? Securitization and the Incentives for Information Production. Journal of Financial Economics, 108, 565-584. https://doi.org/10.1016/j.jfineco.2013.02.005

[10] Ashcraft, A.B. and Schuermann, T. (2007) Understanding the Securitization of Subprime Mortgage Credit. Social Science Electronic Publishing, 2, 318.

[11] Kawai, K. (2015) Reputation for Quality and Adverse Selection. European Economic Review, 76, 47-59. https://doi.org/10.1016/j.euroecorev.2015.02.001

[12] Peng, S.Y. (2016) Information Game and Supervision-Information Asymmetry Risk Analysis in China's Asset Backed Securitization. Journal of China Social Science Graduate School, No. 3, 67-72.

[13] Brealey, R., Leland, H.E. and Pyle, D.H. (1977) Informational Asymmetries, Financial Structure, and Financial Intermediation. Journal of Finance, 32, 371-387.

https://doi.org/10.1111/j.1540-6261.1977.tb03277.x 